\title{
Usefulness of sheath lifting after saline injection technique for colorectal endoscopic submucosal dissection
}

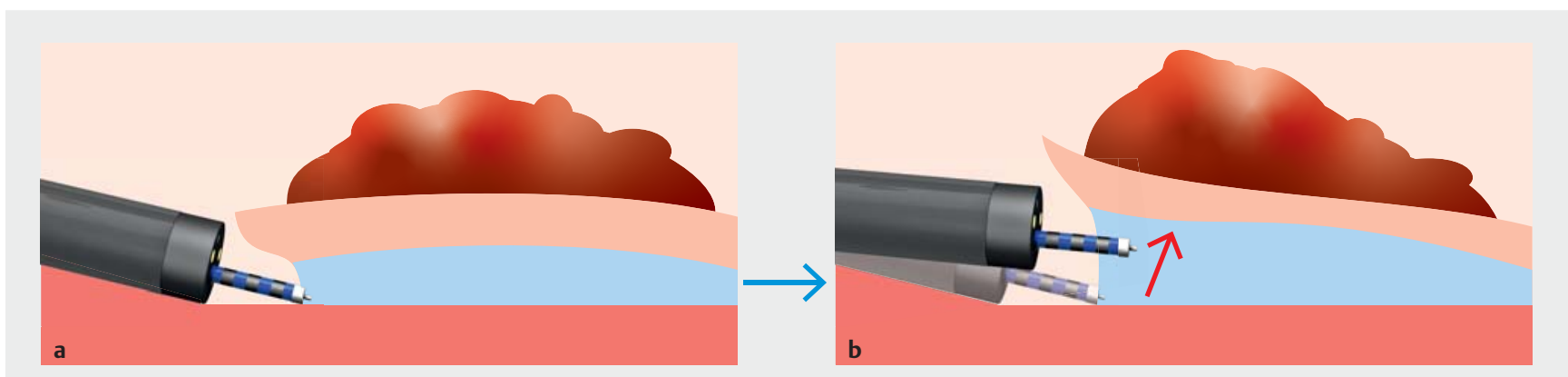

- Fig. 1 Schematic of the "sheath lifting after saline injection" technique. a Cutting direction is toward to the muscle layer. b After injection of normal saline into the submucosal layer, the sheath of the ESD knife is used to lift the submucosal layer away from the muscle layer.

Although colorectal endoscopic submucosal dissection (ESD) enables high en bloc resection regardless of tumor size, it is still a challenging procedure because of its technical difficulties, relatively long procedure time, and high rates of perforation [1-3]. One of the most important things to prevent perforation during colonic ESDs is to maintain the cutting direction of the ESD knife parallel to the muscle layer to avoid dissecting into this layer. In clinical practice, however, the angulated, narrow colon and peristalsis can make it difficult to keep the cutting direction parallel to the muscle layer. The "sheath lifting after saline injection" technique involves using the sheath of the ESD knife to lift the submucosal layer away from the muscle layer just after injecting normal saline into the submucosal layer (> Fig.1). This technique has three steps. First, normal saline is injected into the submucosal layer via ESD knives that have a water jet function, such as the FlushKnife BT-S (Fujifilm Co., Tokyo, Japan) [4]. Second, the sheath of the ESD knife is inserted into the submucosal layer and the length of the ESD knife is adjusted [5]. Third, the submucosal layer is lifted with the sheath and then cut towards the larger space of the colonic lumen. - Video 1 shows a colonic ESD case using this technique. After mucosal incision, we found that the cutting direc-

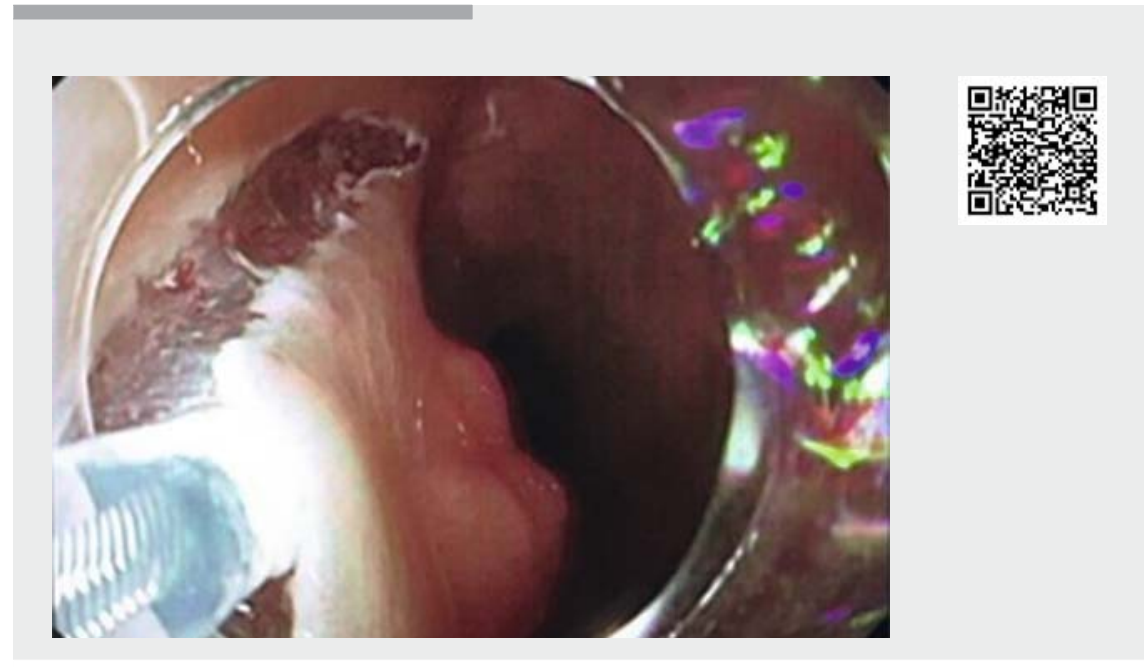

Video 1 Colonic endoscopic submucosal dissection using the sheath lifting after saline injection technique.

tion of the ESD knife was toward the muscle layer because the muscle layer seemed to be going upward. To overcome this, we performed the sheath lifting after saline injection technique ( Fig. 2).

The sheath lifting after saline injection technique is effective whenever endoscopists are unable to keep the cutting direction of the ESD knife parallel to the muscle layer when making the mucosal flap or during dissection of the submucosal layer.
Endoscopy_UCTN_Code_TTT_1AQ_2AC

\section{Competing interests}

The authors declare that they have no conflict of interest. 

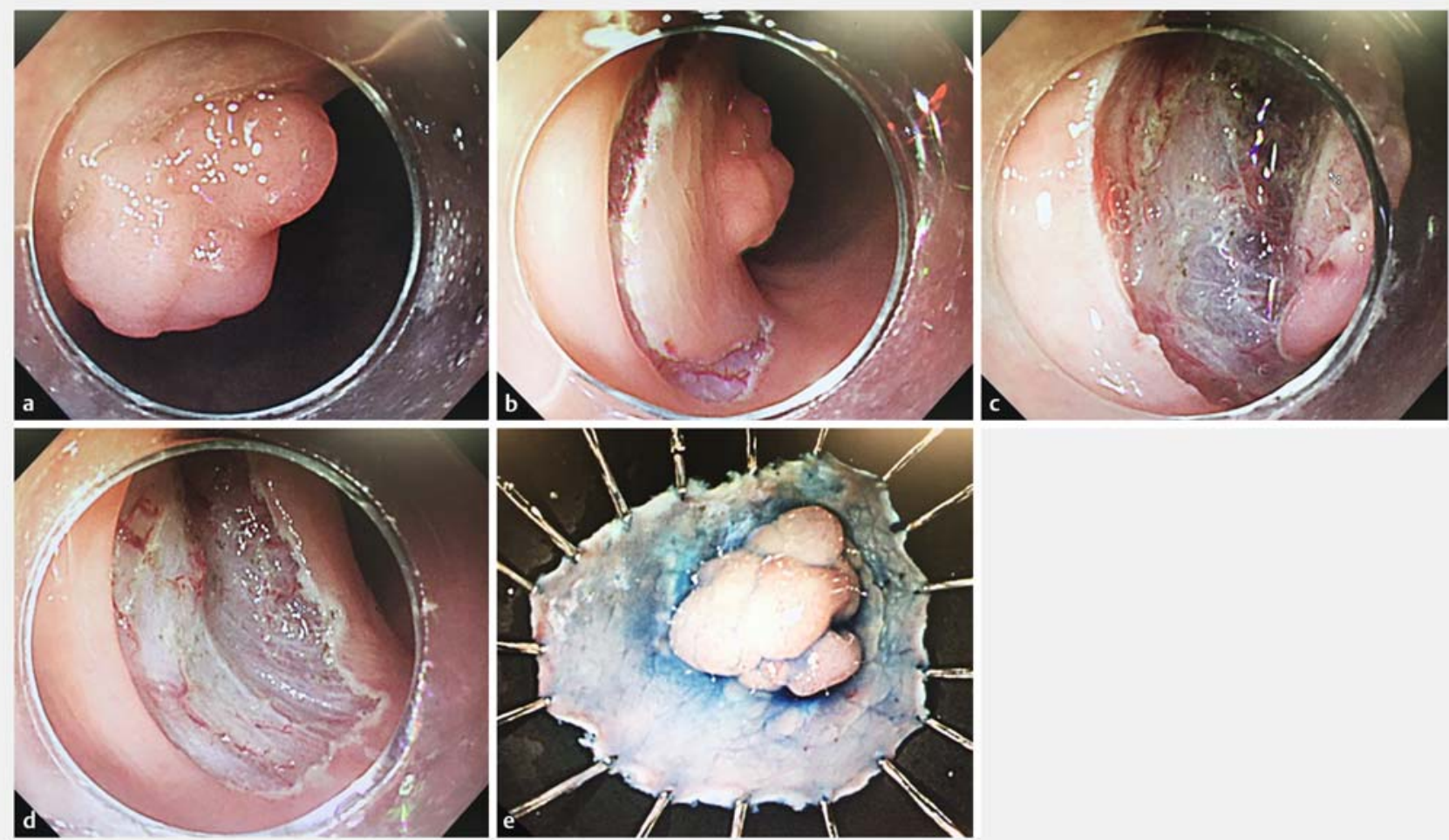

Fig. 2 Illustrative case of the use of the sheath lifting after saline injection technique. a The tumor was type Is, $20 \mathrm{~mm}$ in size, and located on the rectum. b Appearance after mucosal incision. c Appearance after making the mucosal flap. $\mathbf{d}$ En bloc resection achieved. e Resected specimen.

The authors

Taiji Yoshimoto', Tomoatsu Yoshihara², Kenichiro Motozato², Masanao Uraoka², Hiroshi Takihara², Taro Inoue ${ }^{2}$, Akira Asano ${ }^{1}$

1 Department of Gastroenterology, Musashino Tokushukai Hospital, Tokyo, Japan

2 Department of Gastroenterology, Kishiwada Tokushukai Hospital, Kishiwada, Japan

\section{Corresponding author}

\section{Taiji Yoshimoto, MD}

Department of Gastroenterology, Musashino Tokushukai Hospital, 3-5-48, Mukodaicho, Nishitokyo-shi, Tokyo 188-0013, Japan jyfrk268@yahoo.co.jp

\section{References}

[1] Saito Y, Uraoka T, Yamaguchi Y et al. A prospective, multicenter study of 1111 colorectal endoscopic submucosal dissections (with video). Gastrointest Endosc 2010; 58: 1727-1736

[2] Oka S, Tanaka S, Kanao H et al. Current status in the occurrence of postoperative bleeding, perforation and residual/local recurrence during colonoscopic treatment in Japan. Dig Endosc 2010; 22: 376-380

[3] Tanaka S, Kashida H, Saito Y et al. Japan Gastroenterological Endoscopy Society guidelines for colorectal endoscopic submucosal dissection/endoscopic mucosal resection. Dig Endosc 2020; 32: 219-239

[4] Takeuchi Y, Uedo N, Ishihara R et al. Efficacy of an endo-knife with a water-jet function (Flushknife) for endoscopic submucosal dissection of superficial colorectal neoplasms. Am J Gastroenterol 2010; 105: 314-322

[5] Yoshimoto T, Takihara H, Yoshihara T et al. Usefulness of "Nelaton Attachment" for endoscopic submucosal dissection of colorectal neoplasms. Endosc Int Open 2019; 7: E1187-E1191

\section{Bibliography}

Endoscopy 2021; 53: E207-E208

DOI 10.1055/a-1244-9192

ISSN 0013-726X

published online 11.9.2020

(c) 2020. Thieme. All rights reserved.

Georg Thieme Verlag KG, Rüdigerstraße 14, 70469 Stuttgart, Germany

\section{ENDOSCOPY E-VIDEOS}

https://eref.thieme.de/e-videos

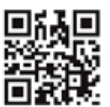

Endoscopy E-Videos is a free access online section, reporting on interesting cases and new techniques in gastroenterological endoscopy. All papers include a high quality video and all contributions are freely accessible online.

This section has its own submission website at https://mc.manuscriptcentral.com/e-videos 